\title{
Thorax
}

Editorials

\section{Platelet activating factor revisited}

\author{
K F Chung
}

In the early 1980s the discovery and isolation of a new lipid mediator, platelet activating factor (PAF), led to a lot of activity and excitement in the inflammation world. PAF, which is a family of structurally related ether-linked phospholipids, is formed from the action of phospholipase $\mathrm{A}_{2}$ and acetyltransferase on membrane alkylacyl phospholipids. PAF was found to possess many properties that made it well suited as a proinflammatory mediator of inflammation in many inflammatory diseases. ${ }^{1}$ Interest in its potential role as a mediator of asthma was fuelled by the observations that it induced airway microvascular leakage, bronchconstriction, and bronchial hyperresponsiveness. In addition, PAF could activate a wide variety of cells including neutrophils, eosinophils, and endothelial cells, and was also found to have potent chemoattractant properties for eosinophils. With the discovery of PAF receptor antagonists, the hypothesis that PAF was involved in chronic asthma was tested. In two studies of moderate to severe asthmatic patients no positive clinical benefit was demonstrated with two different PAF receptor antagonists, ${ }^{23}$ casting doubt on the contribution of PAF to the pathophysiology of chronic asthma despite the fact that PAF or its metabolite or precursor, lyso-PAF, is released in the airways of patients with asthma. It has been argued that the potency of the receptor antagonists may not have been adequate in the in vivo situation, or these antagonists may not be blocking the effects of other bioactive PAF homologues acting perhaps at different PAF receptor subtypes. A preliminary study performed in Japan indicated that a higher dose of one of the two antagonists used, WEB 2086, provided some benefit in steroid-dependent asthmatic patients. ${ }^{4}$ However, enthusiasm for studying PAF antagonists in asthma has waned. Despite this, further interesting observations continue to be reported, particularly with relation to its potential role in asthma, including the paper published by Shindo et al in this issue of Thorax. ${ }^{5}$

\section{PAF and ventilation-perfusion distribution}

Rodriguez-Roisin and colleagues have recently extended the effects of PAF in man by studying its actions on pulmonary gas exchange. ${ }^{67}$ In both normal and asthmatic subjects inhaled PAF induced small falls in arterial $\mathrm{PO}_{2}$ with more profound changes in arterial-alveolar $\mathrm{Po}_{2}$ that were entirely caused by ventilation-perfusion (V/Q) mismatch. The pattern of $\mathrm{V} / \mathrm{Q}$ mismatch was similar to that commonly found in patients with acute severe asthma, which has led to the hypothesis that PAF could underlie the hypoxaemia seen in this condition. Acute severe asthma is also characterised by intense oedema and mucus plugging which could be initiated by PAF. PAF-induced ventilationperfusion mismatch was not related to airway constriction because changes in pulmonary resistance induced by PAF were rather small and larger degrees of bronchoconstriction induced by methacholine did not cause much V/Q imbalance. These abnormalities in $\mathrm{V} / \mathrm{Q}$ could have resulted from alterations in microvascular exudation of plasma in the small airways induced by PAF. ${ }^{8}$

\section{Degradation of PAF}

Being a potent bioactive mediator, it makes sense that PAF can be degraded rapidly by PAF acetylhydrolase which would therefore limit the activity of PAF. A decrease in PAF acetylhydrolase activity would lead to greater inflammatory responses induced by endogenously released PAF. Recent studies in Japan have examined the presence of respiratory symptoms in asthmatic children and the activity of serum PAF acetylhydrolase. ${ }^{9}$ These investigators found that $4 \%$ of a healthy Japanese population had a deficiency of this enzyme and that, amongst asthmatic children, the severity of symptoms was greater in those with PAF acetylhydrolase deficiency. More recently, the inherited serum PAF acetylhydrolase deficiency was found to be the result of a point mutation in exon 9 which leads to complete abolition of enzymatic activity. ${ }^{10}$ Whether these individuals are more prone to inflammatory conditions such as asthma can only be determined by prospective studies. Perhaps of more relevance is whether this deficiency could lead to more severe asthma in asthmatic patients.

\section{Proinflammatory effects of PAF}

The study by Shindo and colleagues further extends the well known proinflammatory effects of PAF. They have found that PAF can prime neutrophils from asthmatic patients, but not from normal volunteers, to release more products of 5-lipoxygenase (5-LO) - namely $\mathrm{LTB}_{4}$ and 5HETE - when these cells are activated by calcium ionophore. Shindo et al propose that this priming effect on 5LO activity is secondary to the enhancement of calcium influx by PAF, but there were no differences in PAFinduced production of $\mathrm{LTB}_{4}$ between normal and asthmatic neutrophils. It is of interest that preincubation of neutrophils with granulocyte-macrophage colony-stimulating factor (GM-CSF) can enhance the ability of PAF to stimulate leukotriene synthesis by increasing both arachidonic acid availability and 5-lipoxygenase activity. ${ }^{11}$ Thus, a priming effect of GM-CSF on neutrophils which in turn primes the effects of PAF is plausible and would represent a real cascade effect on the final neutrophil response. IgEdependent release of $\mathrm{LTC}_{4}$ and histamine from human basophils is also enhanced by PAF after preincubation with GM-CSF. ${ }^{12}$ Shindo et al have also previously shown that 
PAF primes $\mathrm{LTC}_{4}$ release from stimulated eosinophils from asthmatic patients. ${ }^{13}$

These observations, coupled with the results of the present study, indicate that PAF may play an amplifying role in the chronic inflammatory process of asthma by acting on many cell types. It remains to be explained why the clinical studies with PAF receptor antagonists have not shown major clinical benefit for asthmatic patients when reasonable bioactive levels of PAF and lyso-PAF can be detected in patients with chronic asthma. ${ }^{14}{ }^{15}$ Continuing interest in the actions and mechanisms of action of PAF may give further insight into this question.

National Heart and Lung Institute

at Imperial College School of Medicine

K F CHUNG

and Royal Brompton Hospital,

London SW3 6LY, UK

1 Chung KF. Platelet-activating factor in inflammation and pulmonary disorders. Clin Sci 1992;83:127-38.

2 Kuitert LM, Angus RM, Barnes NC, Barnes PJ, Bone MF, Chung KF, et al. Effect of a novel potent platelet-activating factor antagonist, Modipafant, in clinical asthma. Am ₹ Respir Crit Care Med 1995;151:1331-5.

3 Spence DP, Johnston SL, Calverley PM, et al. The effect of the orally active platelet-activating factor antagonist WEB 2086 in the treatment of asthma. Am 7 Respir Crit Care Med 1994;149:1142-8.

4 Tamura G, Takishima T, Mue S, et al. Effectiveness of a potent platelet activating factor (PAF) receptor antagonist, WEB 2086, on asthma: a multicenter, double-blind, placebo-controlled study. Eur Respir f 1994; $152 \mathrm{~s}$

5 Shindo K, Koide K, Fukumura M. Enhancement of leukotriene $B_{4}$ release in stimulated asthmatic neutrophils by platelet activating factor. Thorax 1997;52:1024-9.

6 Rodriguez-Roisin R, Felez MA, Chung KF, et al. Platelet-activating factor causes ventilation-perfusion mismatch in humans. F Clin Invest 1994;93: $188-94$

7 Felez MA, Roca J, Barbera JA, Santos C, Rotger M, Chung KF. Inhaled platelet-activating factor worsens gas exchange in mild asthma. Am $\mathcal{F}$ Respir Crit Care Med 1994;150:369-73.

8 Rodriguez-Roisin R. Acute severe asthma: pathophysiology and pathobiology of gas exchange abnormalities. Eur Respir f 1997;10:1359-71.

Miwa M, Miyake T, Yamanaka T, et al. Characterization of serum plateletactivating factor (PAF) acetylhydrolase. $\mathcal{F}$ Clin Invest 1988;82:1983-91.

10 Stafforini DM, Satoh K, Atkinson DL, et al. Platelet-activating factor acetylhydrolase deficiency. A missense mutation near the active site of an anti-inflammatory phospholipase. F Clin Invest 1996;97:2784-91.

11 McColl SR, Krump E, Naccache PH, et al. Granulocyte-macrophage colony stimulating factor increases the synthesis of leukotriene B4 by human neutrophils in response to platelet-activating factor. F Immunol 1991;141 1204-11.

12 Brunner T, De Weck A, Dahinden CA. Platelet-activating factor induces mediator release by human basophils primed with IL-3, granulocytemacrophage colony-stimulating factor or IL-5. F Immunol 1991;147:23742.

13 Shindo K, Koide K, Hirai Y, Sumitomo M, Fukumura M. Priming effect of platelet activating factor on leukotriene $\mathrm{C} 4$ from stimulated eosinophils of asthmatic patients. Thorax 1996;51:155-8.

14 Stenton SC, Court EN, Kingston WP, et al. Platelet-activating factor in bronchoalveolar lavage fluid from asthmatic subjects. Eur Respir 7 1990; 3:408-13.

15 Chan-Yeung M, Lam S, Chan H, Tse KS, Salari H. The release of plateletactivating factor into plasma during allergen-induced bronchoconstriction. $\mathcal{F}$ Allergy Clin Imunol 1991;87:667-73. 